\title{
Utilização de recursos informacionais na educação ${ }^{1}$
}

\section{Silvana Beatriz Bueno}

\section{Bibliotecária. Mestre em Ciência da Informação. Especialista em Gestão de Bibliotecas}

A pesquisa está inserida no contexto educacional e se propôs a compreender como ocorrem a busca, a seleção, o acesso e o uso de fontes de informação pelos professores do Ensino Fundamental da Escola, e sua relação com as atividades de ensino desenvolvidas. Os resultados do uso de fontes de informação na prática de ensino evidenciaram que a atividade propiciou o diálogo entre professor e alunos, e que houve maior interesse dos alunos, resultados positivos na aprendizagem e melhor qualidade no ensino.

Palavras-chave: Fontes de informação; Professores; Educação.

\section{Use of informational resources in education}

The research described in the article approaches the educational context and its purpose is to understand how the search, selection, access and use of information sources by Elementary and Middle School teachers take place and relates to the teaching activities developed in the school. The results of the use of information sources in the teaching practice showed that the activity fostered the dialogue and there was a greater interest by the students, positive results in learning and a better quality in teaching.

Keywords: Information sources; Teachers; Education.

Recebido em 26.03.2008 Aceito em 12.03.2009

\footnotetext{
${ }^{1}$ Este artigo é parte da Dissertação de Mestrado em Ciência da Informação, do Programa de PósGraduação em Ciência da Informação, Universidade Federal de Santa Catarina, defendida em 08 de março de 2007.
} 


\section{Introdução}

A Sociedade do Conhecimento apresenta mudanças na estrutura de funcionamento das escolas devido às novas mídias e às tecnologias de comunicação e informação, alterando o modo de acesso e de uso da informação. O termo Sociedade do Conhecimento é entendido como a etapa no desenvolvimento da civilização que se caracteriza por uma proporção alta de trabalhadores do conhecimento e em que a educação constitui o ponto fundamental da sociedade (ASSOCIAÇÃO PARA A PROMOÇÃO E DESENVOLVIMENTO DA SOCIEDADE DA INFORMAÇÃO APDSI, 2005).

Os recursos informacionais ou as fontes de informação são importantes para o ensino; seu uso regular, adequado e apropriado é requisito indispensável para a obtenção do sucesso no processo de aprendizagem. Ao considerar que a educação escolar visa fomentar o aprendizado em diferentes níveis, busca oferecer qualidade educacional e requer fontes diversificadas de informação, cada vez mais organizações buscam o desenvolvimento do conhecimento, o progresso tecnológico, a inovação e a criatividade.

A globalização, "processo de integração dos mercados que resulta da liberalização das trocas, da expansão da concorrência e dos impactos das tecnologias da informação e comunicação à escala planetária" (APDSI, 2005, p. 39), juntamente com a revolução informacional, provocou rupturas na sociedade. O acesso à informação é um dos fatores diferenciais entre países desenvolvidos e em desenvolvimento. Entende-se por acesso à informação, a "possibilidade de se obter e utilizar a informação presente em locais de armazenamento públicos, nomeadamente na Internet, sem restrições de ordem social, financeira ou de qualquer natureza". (APDSI, 2005, p. 4).

Este artigo refere-se à pesquisa de mestrado realizada na Escola Desdobrada Municipal João Francisco Garcez, Florianópolis (SC), com o objetivo de compreender como ocorre a busca, a seleção, o acesso e o uso de fontes de informação pelos professores do Ensino Fundamental, e sua relação com as atividades de ensino desenvolvidas. A partir dos conhecimentos das fontes utilizadas pelos professores também foi de interesse saber qual o motivo que os leva a utilizar determinada fonte de informação. A biblioteca escolar se inclui como fonte de informação e local especializado para a busca de recursos de informação, por isso procurouse averiguar o seu papel na busca, na seleção, no acesso e no uso da informação pelos professores.

Para tanto, buscaram-se subsídios teóricos na Ciência da Informação e na Educação para abordar os principais tópicos referentes ao comportamento informacional dos professores. Esta pesquisa contribui para a Ciência da Informação ao abranger como objeto de mediação a biblioteca escolar e sua participação nos processos e suportes informacionais e na dinâmica dos fluxos de informação. Do mesmo modo, 
foi possível contribuir para a Educação ao refletir criticamente sobre os recursos informacionais utilizados pelos professores em seus métodos de ensino.

\section{Revisão de literatura}

\subsection{Contexto educacional}

A Lei de Diretrizes e Bases da Educação Nacional (LDB) (BRASIL, 1996), denominada Lei Darcy Ribeiro, surgiu da necessidade dos educadores em ajustar a legislação aos processos de ensino. Abrange, entre outras questões, a formação do educador, a estrutura institucional e pedagógica da escola e seus desafios.

Das atribuições dos profissionais da educação, a LDB relaciona: participar na elaboração do projeto político-pedagógico da instituição de educação e de seus cursos, programas ou atividades; elaborar e cumprir o respectivo plano de trabalho, zelar pela aprendizagem dos educandos; cumprir os dias letivos, ministrar as aulas programadas e participar dos períodos destinados ao planejamento, à avaliação, ao desenvolvimento profissional e às demais atividades escolares extra-classe; estabelecer, com o apoio dos demais agentes especializados da instituição, estratégias de recuperação para os alunos de menor rendimento; colaborar nas atividades de articulação da escola com as famílias e a comunidade (SANTA CATARINA, 1998).

Demo (1997) considera que a LDB trata o professor como eixo central da qualidade da educação. Afirma que o professor, enquanto orientador, cumpre função essencial porque a aprendizagem precisa de motivação e avaliação constante, e que a educação é um processo de formação. O espaço escolar tornou-se mais flexível, dinâmico e envolvente, sendo administrado pelos próprios profissionais da unidade escolar (MIRANDA, 2000). Esta autonomia da escola requer maior planejamento e exige do professor um melhor preparo. Miranda (2000, p. 59) adverte:

Mas nem sempre esses locais [laboratórios, salas de vídeo, salas de leitura, bibliotecas] para atividades especiais são efetivamente utilizados nas escolas. [...] seja por falta de material, seja por falta de preparo dos professores para utilizar os poucos materiais existentes.

Em meio a esta flexibilidade, surge também a avaliação institucional, com o objetivo de avaliar os resultados obtidos pela prática dos docentes, a presença qualificada e atualizada de bibliotecas, laboratórios, espaços adequados, entre outros (CURY, 1998).

A abordagem acima mostra que o contexto educacional precisa ser investigado, pois ao oferecer mais recursos informacionais para o desenvolvimento de competências, como a habilidade de leitura e 
matemática, é necessário compreender como estes interferem na aprendizagem do indivíduo.

Neste processo, o professor é um sujeito mediador na interação aluno-conhecimento. Ao professor cabe: criar situações de aprendizagem coerentes com esta concepção, estar atendo às várias situações na sala de aula (olhares, tons de voz, demonstrações de afeto ou desafeto), dialogar, ensinar o trabalho em equipe, desenvolver a autonomia no aluno, entre outros cuidados.

Frente ao exposto, sabe-se da carga imposta aos educadores e de sua responsabilidade de cumprir todos os compromissos e conteúdos programáticos, ao mesmo tempo em que se exige deles ter habilidades criativas, saber usar os recursos informacionais, manter-se atualizado e estabelecer estratégias pedagógicas que exijam maior competência dos alunos. Para alcançar estes objetivos, a busca da informação se torna mais criteriosa e diversificada.

\subsection{Perfil dos professores}

O conjunto dos fatores que definem as condições de trabalho, a formação acadêmica, a situação salarial e o estímulo à educação continuada, delimitam o perfil dos professores e se refletem nas práticas profissionais.

Na esfera nacional, a pesquisa "O Perfil dos Professores Brasileiros: o que fazem, o que pensam, o que almejam", realizada pela UNESCO (2004), descreve com riqueza de detalhes as características sociais, econômicas e profissionais dos professores do Ensino Fundamental e do Ensino Médio. A pesquisa objetivou traçar o perfil do professor brasileiro em meio às dificuldades financeiras, de formação, de cultura, e de trabalho e às exigências no domínio das informações nas diferentes áreas do conhecimento (UNESCO, 2004). A referida pesquisa constatou desigualdades regionais e diferenças entre professores de escolas públicas e professores de escolas privadas, tendo estes últimos melhores condições sócio-econômicas.

A pesquisa mostra a necessidade de políticas públicas que estimulem a educação continuada dos professores, haja vista as exigências sobre o ensino e a atuação na sala de aula. A pesquisa conclui que os professores brasileiros compõem um universo de contrastes, de diferenças e de possibilidades (UNESCO, 2004).

Cabe uma reflexão acerca do que seja necessário ao professor em termos de mudanças na sua maneira de ensinar e no uso dos variados recursos de informação. Heide e Stilborne (2000) delimitam que o perfil do professor é o de facilitar o aprendizado, sendo que o aprender torna-se um processo em evolução e não um conjunto de tarefas. No relacionamento do professor com o aluno, seu papel muda de autoridade para o de mediador, conselheiro e guia.

Com relação às formas de trabalhar o ensino pelos docentes, Pereira (2004, p. 58) expõe que a diversificação das atividades trabalhadas em sala de aula é a forma que mais vai "ao encontro dos diferentes estilos 
cognitivos presentes na sala de aula". E acrescenta: "[...] é o professor que, ao organizar toda essa variedade, promove a aprendizagem dos alunos."

Ao mesmo tempo em que se processam novas necessidades surgem recursos de comunicação e informação mais sofisticados que facilitam, desde o planejamento até a execução e a avaliação escolar. Como afirma Paulo Freire (1999), para ensinar é preciso planejar. Segundo Madalena Freire (1997), ao planejar o educador tem claro seus objetivos, sabe o que espera alcançar com aquela atividade e tem como desafio conhecer o conteúdo da matéria e o conteúdo do sujeito. O planejamento é a etapa mais importante de qualquer projeto pedagógico, em que se definem os objetivos, as prioridades e as estratégias (CASARA, 2000). Vera e Silva (1999) afirmam que os passos para planejar podem ser resumidos em: definir os objetivos, selecionar os materiais, estruturar os espaços, as técnicas e o tempo disponível. Ao planejar o professor necessita reservar um tempo para a pesquisa em várias fontes, buscando informações em livros, jornais, revistas, discos, Internet, ou em qualquer fonte ligada ao plano de ensino. $E$ ainda, fazer os registros pessoais para futuras consultas, como relatam Mignot e Cunha (2003).

Considerando a Internet como uma importante fonte de informação, sendo também um instrumento pedagógico que contribui no desenvolvimento de novas atividades educacionais, é importante que os professores assumam um perfil ativo diante da transformação educacional. Neste sentido, "para que ela possa ser usada pedagogicamente na sua plenitude, é fundamental que o educador domine esta tecnologia, ou seja, conheça seu potencial técnico para que possa explorá-la adequadamente" (FAQUETTI; OHIRA, 1999, p. 47).

A escola, com a função de prover formação e utilizar a informação para formar os sujeitos, enfrenta mudanças. Assmann (1998) assinala que a educação só consegue bons resultados quando se preocupa em gerar experiências de aprendizagem, criatividade para construir conhecimento e habilidade para saber acessar fontes de informação sobre os mais variados assuntos. Observa-se que muitas responsabilidades são atribuídas ao professor, e que sua atenção necessita ser redobrada, frente à toda dinâmica da escola. Destaca-se, então, a educação e a formação continuada para os professores poderem ensinar seus alunos a usarem os recursos informacionais e realizarem um melhor uso da informação.

Neste cenário, se faz importante um ambiente interdisciplinar, motivador, crítico e que una a teoria e a prática numa aprendizagem de reconstrução permanente, fazendo parte deste processo a equipe escolar.

\subsection{Recursos informacionais na educação}

Cunha (2001) afirma que o conceito de fonte de informação é muito amplo e envolve os mais diversos tipos de materiais que, analisados, confirmem conhecimento e façam parte de uma compilação bibliográfica.

As fontes de informação são divididas em três categorias: fontes primárias, secundárias e terciárias. As fontes primárias são os documentos 
que geram análises para posterior criação de informações e servem para aprofundar o conhecimento de um tema. São aquelas que contêm informações originais. As fontes secundárias são as obras nas quais as informações já foram elaboradas, ou seja, representam a informação processada e organizada. São documentos estruturados segundo padrões rigorosos. As fontes terciárias têm a função de guiar o usuário para as fontes primárias e secundárias. São documentos que exercem a função indicativa, auxiliando o pesquisador a encontrar um dado (CAMPELLO; CAMPOS, 1993; SOUZA, 1997; CUNHA, 2001).

Faquetti, Vanin e Blattmann (2005) destacam que, no desenvolvimento das atividades de ensino, saber como localizar e utilizar as fontes de informação torna-se o diferencial de qualidade. $O$ uso de várias fontes em pesquisa permite conseguir informações importantes na formulação de idéias e no desenvolvimento de autonomia para a obtenção do conhecimento. Os alunos serão mais capazes de selecionar as informações relevantes conforme suas necessidades. Kuhlthau (2004) enfatiza que, ao explorar as diversas fontes de informação da biblioteca e os recursos oferecidos, o aluno vivenciará experiências no uso dos diferentes arranjos das fontes de informação e habilidades em outras fontes especializadas.

Dentre as fontes de informação utilizadas na educação fundamental destacam-se: a literatura infantil e infanto-juvenil; as obras de referência; os periódicos; os multimeios; o acervo técnico e a Internet. Hillesheim e Fachin (2000) acrescentam ainda os gibis, os folhetos, as gravuras e os jogos educativos como fontes que compõem o acervo da biblioteca.

\section{Metodologia da pesquisa}

A metodologia envolve a abordagem qualitativa de caráter bibliográfico, descritivo e etnográfico. A pesquisa bibliográfica é o tipo de pesquisa utilizada para a fundamentação da literatura e o suporte teórico na análise e interpretação dos dados. Conforme Gil (1991), a pesquisa bibliográfica faz parte do referencial teórico da pesquisa, exigência nos trabalhos científicos. Barros e Lehfeld (2000), Demo (2000) e Salomon (2001) apontam a necessidade de se realizar o levantamento bibliográfico para identificar a visão do assunto por outros pesquisadores e a maneira ou método de enfocar ou interpretar o tema, para incorporar conceitos e conhecer os pontos de vista.

Segundo Gil (1991), as pesquisas descritivas objetivam a exposição e a explicação das características da população ou do fenômeno em estudo. Incluem pesquisas que objetivam levantar as atitudes de uma população. Instituições educacionais geralmente são foco destas pesquisas. Na pesquisa descritiva o pesquisador descreve o objeto de pesquisa e procura descobrir características do fenômeno, natureza, causas, relações com outros fatos (BARROS; LEHFELD, 2000). Compreende a descrição, o registro, a análise e a interpretação dos fenômenos, enfocando como uma pessoa, grupo ou coisa se conduz (SALOMON, 1977). 
De acordo com Mattos (2001), a etnografia é uma abordagem de investigação científica que procura analisar um grupo particular de pessoas que estão associadas de alguma maneira, sendo formado por poucos ou vários elementos. Permite estudar os padrões do comportamento humano expressos no cotidiano, estudando os fatos dentro de um contexto de interação entre as pessoas e o ambiente em que este contexto está inserido. Compreende o estudo dos costumes de um grupo de pessoas de uma unidade social, seja uma vila, uma escola, um hospital, entre outros. O grande foco da etnografia é a descrição mais completa possível sobre as ações de um grupo em particular, interessando-se assim pelo estudo local.

Para a coleta de dados utilizou-se um questionário de perguntas semi-abertas com questões relacionadas a fatos e dados de ordem pessoal; perguntas sobre padrões de ação, relativas a considerações a respeito das ações praticadas, com o intuito de buscar um reflexo do comportamento provável diante de situações específicas; e perguntas referentes às razões conscientes de crenças, orientações ou comportamentos, conforme a categorização de Gil (1994). Segundo Barros e Lehfeld (2000), o questionário é o instrumento mais usado para o levantamento de informações. Além do questionário com perguntas semi-abertas realizaram-se contatos informais com os participantes da pesquisa.

O estudo de Mestrado teve como ambiente de pesquisa a Escola Desdobrada Municipal João Francisco Garcez, Florianópolis (SC). A escola atende alunos de $1^{a}$ a $4^{a}$ série do Ensino Fundamental. A população da pesquisa se constituiu em todos os professores da escola, que é composta de 12 profissionais educadores. Os sujeitos da pesquisa foram os professores efetivos, os professores efetivos readaptados e os professores substitutos. Os professores foram escolhidos como sujeitos da pesquisa pelo seu caráter influenciador na formação do leitor e no uso dos recursos informacionais, e pela sua importância no processo de aprendizagem.

\section{Principais resultados da pesquisa}

O estudo da utilização de recursos informacionais pelos professores demonstrou que as fontes de informação para atualização pessoal relacionadas ao processo ensino-aprendizagem e aos conteúdos pedagógicos são: a Internet diariamente, para pesquisas e e-mail, as gravuras e imagens semanalmente, o livro científico quinzenalmente e as enciclopédias mensalmente.

Com relação às fontes de informação prioritárias nas atividades com os alunos os professores preferem para uso diário o livro didático, o livro científico, a Internet, o livro infantil e os jogos educativos. Semanalmente, os professores acrescentam as revistas como fontes prioritárias além das mencionadas para uso diário. Constata-se que a freqüência de uso destas fontes está delimitada ao uso diário e semanal e pode-se concluir que os professores priorizam as atividades diárias e semanais. A adequação das fontes ao planejamento escolar e aos objetivos propostos, e o fato de 
serem recursos de pesquisa e ludicidade, são os motivos que levam os professores a eleger estas fontes de informação como prioritárias. Em se tratando de fontes de informação utilizadas para se trabalhar um conteúdo novo relacionado ao processo ensino-aprendizagem, além das já mencionadas os professores acrescentam o dicionário, pois relacionam seu uso à escrita, nas atividades com os alunos para sanar dúvidas na grafia, permitir saber o significado das palavras e realizar pesquisas.

Os professores localizam as fontes de informação para preparar suas aulas no acervo pessoal, na biblioteca da escola e na Internet. Eles preferem seu próprio acervo bibliográfico ao elaborarem suas atividades de ensino. Mesmo estando em segundo lugar, a biblioteca apresentou índice significativo, o que pode ser um indicador de que a biblioteca da escola atende às necessidades informacionais dos professores. Os professores utilizam a Internet como terceiro recurso informacional.

Quanto aos critérios para a seleção de fontes de informação para o processo ensino-aprendizagem, os professores selecionam fontes que tenham um grau de confiabilidade, atualidade e conveniência. Elegem como critérios mais importantes a credibilidade da fonte, a atualidade da fonte e sua adequação com a faixa etária do aluno.

Os professores não se limitam ao uso e à aplicação de uma única fonte de informação, estando estas sempre ligadas a alguma ação pedagógica. Os professores utilizam as fontes de informação na capacitação pedagógica; na brinquedoteca; ao trabalhar o conteúdo curricular; no trabalho de artes; no trabalho com projetos; para fazer pesquisas; para estimular a imaginação; ao trabalhar o texto, a oralidade, a leitura, a escrita, a compreensão e a interpretação; e ao trabalhar a coordenação nas aulas de Educação Física. Na opinião dos professores, os resultados do uso de fontes de informação na prática de ensino propiciaram diálogo. Houve maior interesse dos alunos, com resultados positivos na aprendizagem e melhor qualidade do ensino.

Todos os professores utilizam a biblioteca da escola, principalmente por sua localização, pelo acervo, pela organização, pelo apoio pedagógico e pelo estímulo à leitura. Costumam freqüentar a biblioteca semanalmente ou quinzenalmente. Os professores entendem a biblioteca como um apoio pedagógico, e por isso a usam como local propício para a pesquisa de conteúdo curricular a ser trabalhado em sala de aula; local onde se encontram opções para elaboração do planejamento escolar, local para a busca de materiais para aprimorar e enriquecer seu trabalho. Apesar de evidenciadas algumas deficiências de acervo quanto às necessidades de busca e de acesso à informação, a biblioteca da escola atende às necessidades dos professores.

Ao usar fontes de informação na sala de aula, os professores consideraram que a atividade propicia diálogo, maior interesse dos alunos, resultados positivos na aprendizagem, e facilitam a aula, como também melhoram a qualidade no ensino.

Os resultados do uso de fontes de informação na prática de ensino demonstram que os professores fazem avaliação pedagógica sistematicamente e têm claros seus objetivos. Também demonstram que 
o uso de fontes de informação traz benefícios na aprendizagem dos alunos, que podem ser destacadas: permitir condições para a realização do diálogo, despertar o interesse, provocar a curiosidade por novos recursos informacionais e relacionar conhecimentos anteriores a conhecimentos novos. Esta prática pedagógica é uma forma de desenvolver uma educação que envolva o aluno, o professor, a escola e as diversas fontes de informação, com o intuito de melhorar a aprendizagem.

\section{Considerações finais}

A pesquisa realizada na Escola Desdobrada Municipal João Francisco Garcez teve como objetivo principal compreender como ocorre a busca, a seleção, o acesso e o uso de fontes de informação pelos professores, e sua relação com as atividades de ensino desenvolvidas. O objetivo geral foi alcançado e possibilitou a visão do comportamento dos professores no processo de fluxo da informação. Para caracterizar o ambiente da pesquisa, fornecer o embasamento teórico para a revisão de literatura, procedimentos metodológicos e análise dos resultados, utilizou-se os recursos oriundos da pesquisa bibliográfica.

A pesquisa possibilitou avançar no universo pedagógico e compreender o trabalho dos professores do Ensino Fundamental. Refletiuse sobre o contexto em que estão inseridos, frente às exigências e responsabilidades no ofício da profissão de professor no tempo da Sociedade da Informação e do Conhecimento. Em meio à variedade de fontes de informação na educação, verificaram-se as possibilidades e ações que estes professores desempenham para melhorar a qualidade do ensino.

\section{Referências}

ASSOCIAÇÃO PARA A PROMOÇÃO E DESENVOLVIMENTO DA SOCIEDADE DA INFORMAÇÃO - APDSI. Glossário da Sociedade da Informação. [Portugal]: APDSI, 2005. 122p.

ASSMANN, H. Reencantar a educação: rumo a sociedade aprendente. Petrópolis: Vozes, 1998.

BARROS, A. J. S.; LEHFELD, N. A. S. Fundamentos de metodologia científica: um guia para a iniciação científica. 2. ed. São Paulo : MAKRON, 2000.

BRASIL. Lei n. 9394 de 20 de dezembro de 1996. Lei de diretrizes e bases da educação nacional. DOU de 23 dez. 1996. 8. ed. Florianópolis: SINEP/SC, [200-].

CAMPELLO, B. S.; CAMPOS, C. M. Fontes de informação especializada: características e utilização. 2 ed. Belo Horizonte: Ed. UFMG, 1993.

CASARA, M. A arte de planejar. Nova Escola, São Paulo, v. 15, n. 138, p. 2030, dez. 2000. 
CUNHA, M. B. Para saber mais: fontes de informação em ciência e tecnologia. Brasília: Briquet de Lemos/Livros, 2001.

CURY, C. R. J. Lei de Diretrizes e Bases e perspectivas da educação nacional. Revista Brasileira de Educação, Rio de Janeiro, n. 8, p. 72-85, mai/jun./jul.ago., 1998.

DEMO, P. A nova LDB: ranços e avanços. Campinas, SP: Papirus, 1997. . Metodologia do conhecimento científico. São Paulo: Atlas, 2000.

FAQUETI, M. F.; OHIRA, M. L. B. A Internet como recurso na educação: contribuições da literatura. Revista ACB: Biblioteconomia em Santa Catarina, Florianópolis, v.4, n.4, p. 47-63, jan./dez. 1999.

FAQUETI, M. F.; VANIN, M.; BLATTMANN, U. Apresentação de trabalhos escolares: a biblioteca no processo de aprendizagem. In: CONGRESSO BRASILEIRO DE BIBLIOTECONOMIA, DOCUMENTAÇÃO E CIÊNCIA DA INFORMAÇÃO, 21., Anais...2005, Curitiba, 2005. CD-ROM .

FREIRE, M. Planejamento: sonhar na ação de planejar. In.: FREIRE, M. et al. Avaliação e planejamento: a prática educativa em questão. São Paulo: [S.I.], 1997. p. 54-59.

FREIRE, P. Pedagogia da autonomia: saberes necessários à prática educativa. 12 ed. São Paulo: Paz e Terra, 1999.

GIL, A. C. Como elaborar projetos de pesquisa. 3. ed. São Paulo: Atlas, 1991.

1994.

. Métodos e técnicas de pesquisa social. 4 ed. São Paulo: Atlas,

HEIDE, A.; STILBORNE, L. Guia do professor para a Internet: completo e fácil. 2. ed. Porto Alegre: Artes Médicas, 2000.

HILLESHEIM, A. I. A.; FACHIN, G. R. B. Biblioteca escolar: relato de experiência. Revista ACB: Biblioteconomia em Santa Catarina, Florianópolis, v. 5, n. 5, p. 90-103, jan./dez. 2000.

KUHLTHAU, C. Como usar a biblioteca na escola: um programa de atividades para o ensino fundamental. 2. ed. Belo Horizonte: Autêntica, 2004.

MATTOS, C. L. G. A abordagem etnográfica na investigação científica. Espaço, Rio de Janeiro, jul./dez., p. 42-59, 2001.

MIGNOT, A. C. V.; CUNHA, M. T. S. (Orgs.). Práticas de memória docente. São Paulo: Cortez, 2003.

MIRANDA, G. V. Um olhar sobre a organização do espaço e do tempo. In: MIRANDA, G. V. Um olhar sobre a escola. Brasília: Ministério da Educação, Seed, 2000.

PEREIRA, L. A. Didática, letramento e formação de professores. Pátio, Porto Alegre, ano 8, n. 29, p. 57-60, fev./abr. 2004. 
SALOMON, D. V. Como fazer uma monografia. São Paulo: Martins Fontes, 2001.

- Como fazer uma monografia: elementos e metodologia do trabalho científico. 5. ed. Belo Horizonte: Interlivros, 1997.

SANTA CATARINAL. Lei Complementar Estadual n. 170/1998. Dispõe sobre o Sistema Estadual de Educação. Diário Oficial de Santa Catarina, 7 de agosto de 1998.

SOUZA, F. C. Escrevendo e normalizando trabalhos acadêmicos: um guia metodológico. Florianópolis: Ed. da UFSC, 1997.

UNESCO. O perfil dos professores brasileiros: o que fazem, o que pensam, o que almejam. São Paulo: Moderna, 2004.

VERA e SILVA, Adriana. Planejar: o caminho para a boa aula. Nova escola, São Paulo, n.126, p. 10-17, out. 1999. 